\title{
BMJ Global Health What is considered as global health scholarship? A meta-knowledge analysis of global health journals and definitions
}

\author{
Salma M Abdalla (1D , ${ }^{1}$ Hiwote Solomon (D) , ${ }^{2}$ Ludovic Trinquart, ${ }^{3}$ Sandro Galea ${ }^{1}$
}

\begin{abstract}
To cite: Abdalla SM, Solomon H, Trinquart L, et al. What is considered as global health scholarship? A meta-knowledge analysis of global health journals and definitions. BMJ Global Health 2020;5:e002884. doi:10.1136/ bmjgh-2020-002884
\end{abstract}

Handling editor Seye Abimbola

Received 11 May 2020

Revised 11 August 2020

Accepted 14 August 2020

D Check for updates

(C) Author(s) (or their employer(s)) 2020. Re-use permitted under CC BY-NC. No commercial re-use. See rights and permissions. Published by BMJ.

'Department of Epidemiology, Boston University School of Public Health, Boston, Massachusetts, USA

${ }^{2}$ Doctor of Public Health Program, Boston University School of Public Health, Boston, Massachusetts, USA

${ }^{3}$ Department of Biostatistics, Boston University School of Public Health, Boston, Massachusetts, USA

Correspondence to Dr Salma M Abdalla; abdallas@bu.edu

\section{ABSTRACT}

Despite the rapid growth of the global health field over the past few decades, consensus on what qualifies as global health scholarship or practice remains elusive. We conducted a meta-knowledge analysis of the titles and abstracts of articles published in 25 journals labelled as global health journals between 2001 and 2019. We identified the major topics in these journals by creating clusters based on terms co-occurrence over time. We also conducted a review of global health definitions during the same period.

The analysis included 16413 articles. The number of journals, labelled as global health, and articles published in these journals, increased dramatically during the study period. The majority of global health publications focused on topics prevalent in low-resource settings. Governance, infectious diseases, and maternal and child health were major topics throughout the analysis period. Surveillance and disease outcomes appeared during the 2006-2010 epoch and continued, with increasing complexity, until the 2016-2019 epoch. Malaria, sexual and reproductive health, and research methodology appeared for only one epoch as major topics. We included 11 relevant definitions in this analysis. Definitions of global health were not aligned with the major topics identified in the analysis of articles published in global health journals.

These results highlight a lack of alignment between what is published as global health scholarship and global health definitions, which often advocate taking a global perspective to population health. Our analysis suggests that global health has not truly moved beyond its predecessor, international health. There is a need to define the parameters of the discipline and investigate the disconnect between what is published in global health versus how the field is defined.

\section{INTRODUCTION}

Global health as an academic field has grown dramatically in the past few decades. Departments of global health are now nearly universal in leading Schools of Public Health and many medical schools have groups of faculty who work in 'global health'. ${ }^{2}$ This growth has been accompanied by a similar

\section{Key questions}

What is already known?

- Despite growing dramatically over the past few decades, the margins of what falls under the umbrella of global health scholarship remain elusive.

- Journals labelled as 'global health' journals often do not have a specific methodological or topical focus.

- Definitions of global health are largely dependent on expert opinions, do not explicitly address the power dynamics within the field and are not aligned on a specific methodological or topical focus.

\section{What are the new findings?}

- Topics that predominantly concern low-income and middle-income countries, such as infectious diseases and maternal and child health, are the major topics discussed in global health journals.

- Topics with global significance, such as climate change and non-communicable diseases, do not appear as major topics in publications in global health journals.

- Definitions of global health do not fully align with the major topics published in global health journals.

- The focus of publications in global health journals poses the question of whether global health is simply an extension of international health, rather than a field of its own.

What do the new findings imply?

- There is a need to define the parameters of the discipline and investigate the disconnect between what is published in global health journals versus how the field is defined.

- Global health as a discipline needs to more clearly articulate a global focus in its scholarship and align publications with this focus.

increase in the number of publications dedicated to the field. By way of example, the number of articles using global health in title or abstract in MEDLINE increased by nearly 30-fold between 2001 and 2019. Yet, despiteor perhaps because of-this rapid growth, 
consensus on what falls under the umbrella of global health scholarship or practice remains elusive. ${ }^{3}$

A lack of specificity presents a challenge for any field of scientific inquiry. That challenge may be particularly important for an emerging field that is heavily influenced by donor priorities, who are, in turn, informed by their understanding of the field's scope. There have several recent discussions about the definition and future of the field. ${ }^{4-8}$ These discussions are, however, almost exclusively grounded in expert opinion.

We are not aware of any prior effort to help define the field empirically, assessing the major topics published in the field, and how those have changed over time. Such an effort can evaluate how publications in the field have evolved and offer data that can help inform our thinking about what is considered global health scholarship is, and by extension, what it can be. Meta-knowledge analyses, relying on large quantities of texts to map the distribution and influence of different topics on a scientific field over time, provide an opportunity to fill this empirical gap. $^{9-11}$

Using a previously described meta-knowledge approach, ${ }^{12}$ we aimed to provide an empirical perspective on the topics of concern to journals often labelled as global health journals over the past two decades. We also examined whether commonly used definitions of global health share language that distinguishes the field and whether that language reflects the published literature in global health journals.

\section{METHODS}

\section{Analysis of global health journals}

\section{Selection of journals and articles}

We selected 25 global health-thematic journals for this analysis (list of journals included in the online supplemental file) between 2001 and 2019. Our aim was to examine what is published in journals labelled as global health journals. We identified these journals from three overlapping sources: (a) a review article that included a list of 12 journals that had the terms 'global health' or 'international health' in their titles; (b) a list of 17 journals suggested by the American Journal of Public Health as a potential publisher of commentaries about global health and (c) a review article that included a list of 27 global health journals. ${ }^{1314}$ Out of a total of the 30 candidate journals we selected, we were able to analyse only journals indexed in MEDLINE, due to the structure of the analysis software.

Because we aimed to use the Millennium Development Goals (MDGs) as a benchmark and as only three journals included in our analysis-Tropical Medicine and International Health; Medicine, Conflict and Survival; and Bulletin of WHO-published articles before 2001, we chose 2001 as the starting year for the analysis. We categorised the articles into four periods: the first three periods, 2001-2005, 2006-2010 and 2011-2015, were based on 5-year intervals following the adoption of the
MDGs. The final period, 2016-2019 followed the adoption of the Sustainable Development Goals (SDGs). We analysed the data for each period separately.

\section{Data mining and linguistic processing}

We downloaded the selected records from MEDLINE via PubMed. We combined extracted titles and abstracts for those articles into a single string and discarded words traditionally used to denote the structure of an abstract. Each word in a string was assigned a lemma (dictionary form) using grammatical tagging. We developed a thesaurus that allowed for merging of different spellings of the same word (eg, 'globalization' and 'globalisation') and the abbreviation with the word or phrase itself (eg, 'Community health workers' and 'CHWs').

Each string was then reduced to terms, which refer to either single nouns, sequences of adjectives and nouns, or nouns that belong together (eg, randomized control trial). Each term that occurred multiple times within a string was counted only once. We disregarded any term that occurred less than 10 times overall. To quantify the relevance of each term, the distribution of a term co-occurrences over all terms was compared with the distribution of all co-occurrences over all terms. A larger difference (measured by Kullback-Leibler distance) between the two distributions, indicated a higher relevance of the term. Ultimately, we selected the top $60 \%$ of the terms with the highest relevance to include in the map.

\section{Mapping of main topics of inquiry}

We mapped terms based on their occurrence frequency, network proximity and cluster. Terms appear as nodes in the map. For each term, the node size is proportional to its frequency of occurrence. Terms that rarely occurred together in an article, appear far from each other on the map. Terms related to each other formed a cluster. We then reviewed the terms in each cluster to identify the underlying topic. The size of a cluster in the map indicated its share of terms compared with the total number of terms. We interpreted clusters as major topics in global health $^{15} 16$

\section{Global health definitions}

\section{Selection of definitions}

We examined 12 global health textbooks and 32 peerreviewed articles for relevant definitions of global health, to understand how scholars conceptualise and define global health (details in the online supplemental file). We used this literature to inform our analysis of the key terms used in definitions of global health.

\section{Text mining, calculation of frequencies and word cloud} development

We created a corpus with the raw text from the definitions collected from the literature review. Text mining of the raw data included replacing special characters with space. It also included removing common English words (eg, 'I', 'be', 'do'), numbers, punctuation and extra white 
space. The last step was text stemming that is, reducing words to their root form.

Using the document from the text mining of definitions, we created a word cloud. Word clouds are useful tools that visually summarise text data. Words were allocated based on their frequency in all the included definitions. In this word cloud, we only included words with a frequency of three or more. Frequency also determined the size of a word in the cloud.

\section{Data analysis}

We used R V.3.6.2 to conduct text mining, development of the word cloud, run descriptive analyses and prepare the text string for mapping. ${ }^{17}$ We used Vosviewer V.1.6.14 to quantify term relevance, term clustering and term mapping. ${ }^{18}$

\section{Patient and public involvement}

Patients and/or the public were not involved in the design, conduct, reporting or dissemination plans of this research.

\section{RESULTS}

\section{Article characteristics}

We included 16413 articles in the analysis of journals. Overall, the journals that published the most articles were Tropical Medicine and International Health $(19.6 \%)$ and Bulletin of the WHO (12.6\%). No other journal represented at least $10 \%$ of the publications. There was a sharp increase in the number of articles published per year over the period studied, mostly driven by newer global health journals entering the field. There were almost as many articles published in 2019 (2021 articles) by 24 journals compared with all the articles published between 2001 and 2018 (2220 articles) by 8 journals (figure 1 ).

\section{Mapping of major topics of inquiry}

Between 2001 and 2005, we identified four clusters within 1465 articles. These clusters were governance, infectious diseases, maternal and child health, and malaria (figure 2). The terms 'infection' and 'dhfr' had the most occurrence and relevance in this map, respectively (online supplemental table 1).

Between 2006 and 2010, we also identified four clusters within 2364 articles. The maternal and child health and infectious diseases clusters persisted, with the infectious diseases cluster encapsulating malaria, while the cluster on governance evolved to focus on development. A fourth cluster on surveillance and disease outcomes, with a focus on demographics, emerged during this period (figure 3). The terms 'patient' and 'uncomplicated falciparum malaria' had the most occurrence and relevance in this map, respectively (online supplemental table 2 ).

We identified four clusters between 2011 and 2015 within 5856 articles. The clusters on maternal and child and infectious diseases persisted. The governance cluster evolved to focus on health systems, frameworks and stakeholders. A focus on non-communicable diseases appeared within the surveillance and disease outcomes cluster (figure 4). The terms 'age' and 'SRHR' had the most occurrence and relevance in this map, respectively (online supplemental table 3 ).

For the 2016-2019 period, we identified six clusters within 5080 articles. The infectious diseases and surveillance and disease outcomes clusters persisted. The governance cluster evolved to focus more on institutions, funding, Universal Health Coverage (UHC) and the SDGs. The maternal and child health cluster evolved to focus on measuring maternal and child mortality. In addition, two new clusters appeared, a sexual and reproductive health cluster and a research methodology cluster (Figure 5). The terms 'age' and 'corrigendum' had the

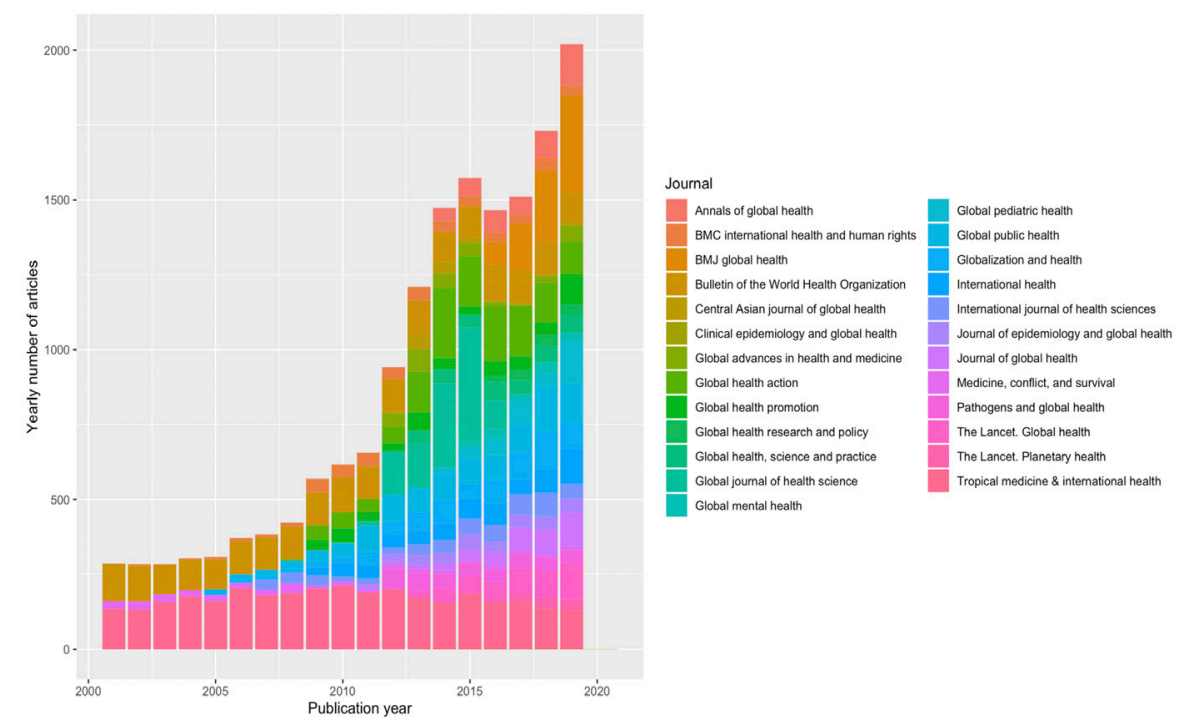

Figure 1 Number of articles published per year from 2001 to 2019 by journal. 


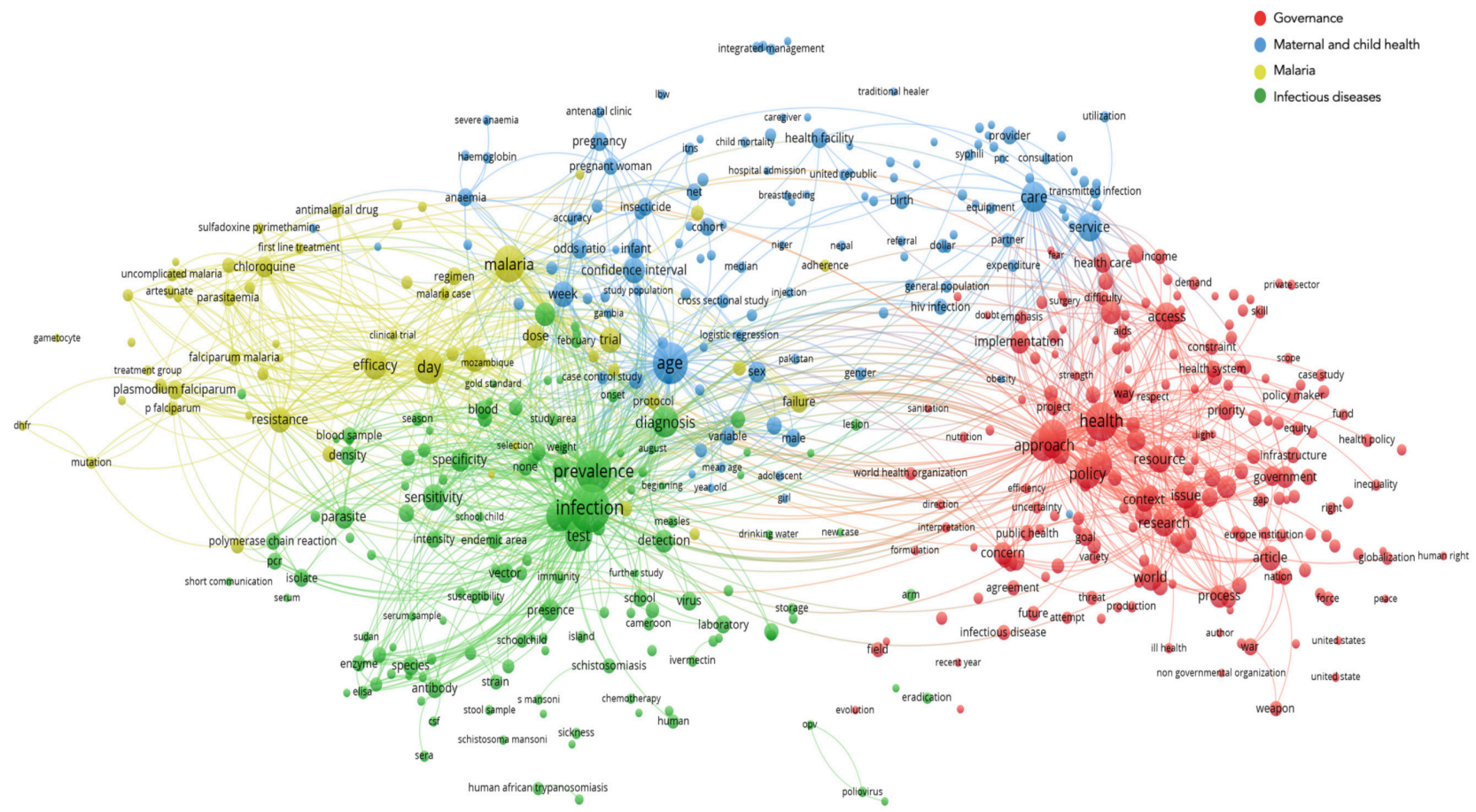

Figure 2 Mapping and clustering of terms in global health journals between 2001 and 2005.

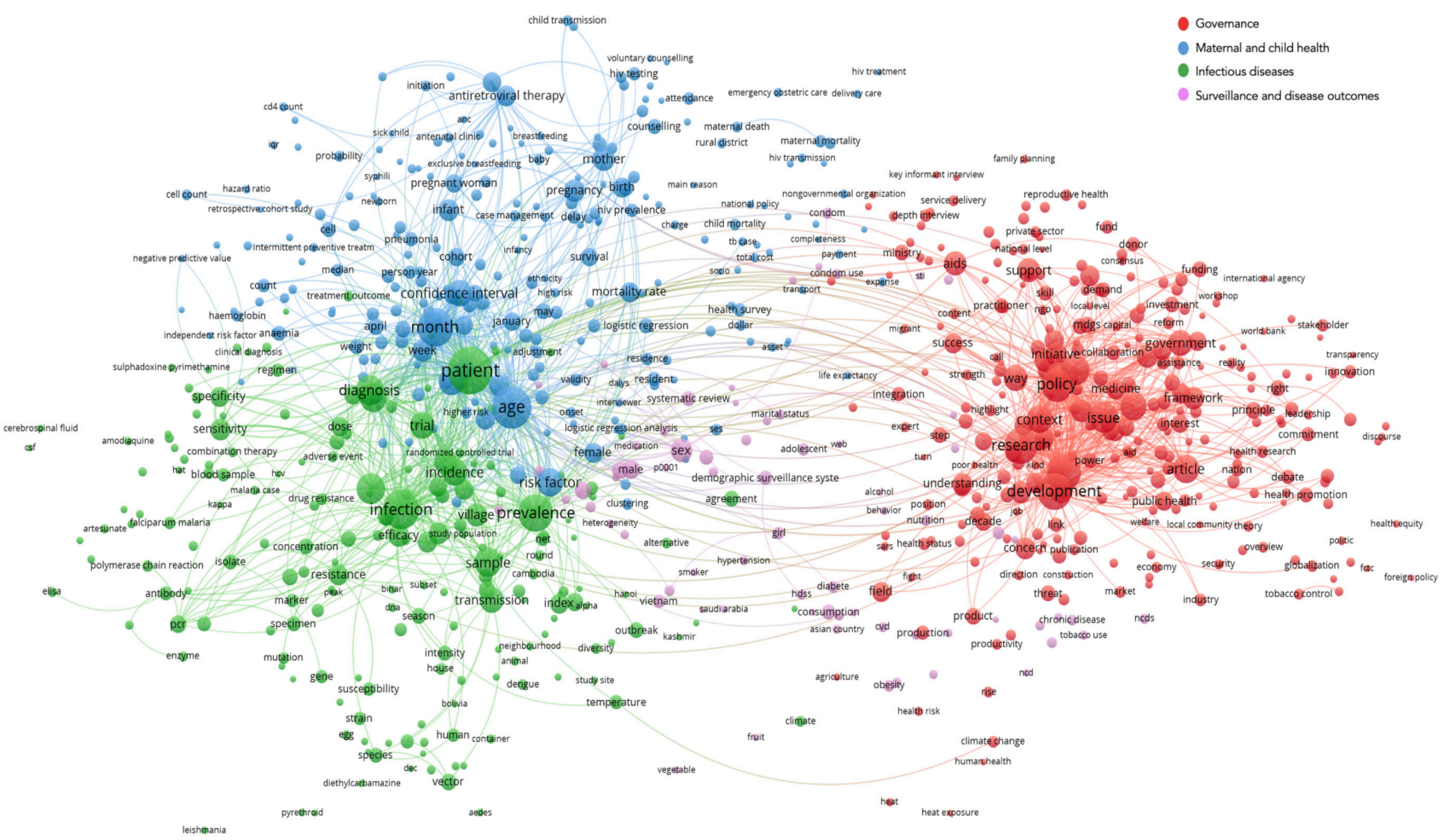

Figure 3 Mapping and clustering of terms in global health journals between 2006 and 2010. 


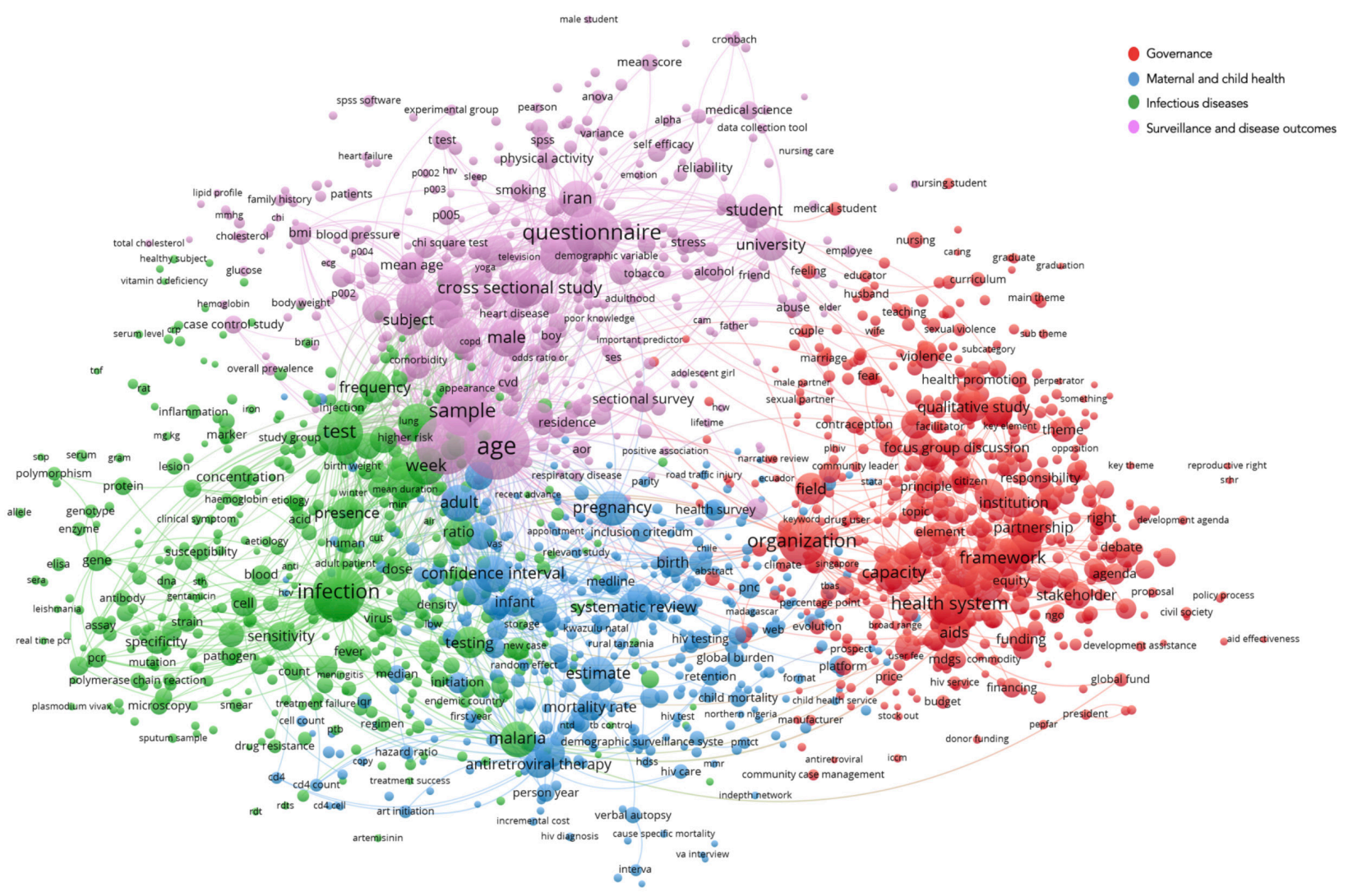

Figure 4 Mapping and clustering of terms in global health journals between 2011 and 2015.

most occurrence and relevance in this map, respectively (online supplemental table 4).

\section{Global health definitions}

We identified 11 relevant definitions of the term global health, which were included in publications that explicitly aim to provide a definition of the term (table 1)..$^{5919-27}$ The majority of definitions were from global health textbooks. There were three definitions from peer-reviewed articles that explicitly aimed to define the term. One definition was often used as the gold standard definition of global health in other reviewed publications. ${ }^{9}$ The most used term in defining the field was 'health', followed by 'disease', then 'global'. However, there was not much agreement on other terms between definitions on the geographical location and topical focus of the field. Particularly, definitions of global health were inconsistent in identifying whether global health referred to scholarship, practice or a combination of the two.

\section{DISCUSSION}

A meta-knowledge analysis of 16413 articles published in 25 global health journals between 2001 and 2019 . Governance, infectious diseases, and maternal and child health were consistent major topics throughout the analysis period. In addition, there was increasing complexity and connections between the main topics published by these journals over time. Comparing the major topics with identified global health definitions suggests a lack of alignment on what is published as global health scholarship and prevailing global health definitions, especially as the major topics published by global health journals focused on diseases relevant to low/middle-income countries (LMICs) rather than global settings.

The literature published in global health journals has been consistently concerned with maternal and child health and infectious diseases, malaria in particular. This likely echoes the adoption of reducing maternal and child mortality rates and combating malaria, along with other infectious diseases, as priority areas for the MDGs in 2000. ${ }^{28}$ Further, funding for maternal and child health has also remained steady over the past two decades. ${ }^{29}$ Importantly, while HIV/AIDS was part of the MDGs and continues to receive a substantial percentage of global funding for health, the topic is not featured prominently as a separate major topic in global health journals. This is likely due to the fact that there are HIV/AIDS specialised journals and scholars who work on the topic prefer to publish in such journals.

Two clusters, surveillance and disease outcomes and governance. were also consistent features of global health journal publications in our analysis. However, the focus of both clusters saw a substantial change in what was researched even during a relatively short 20-year 


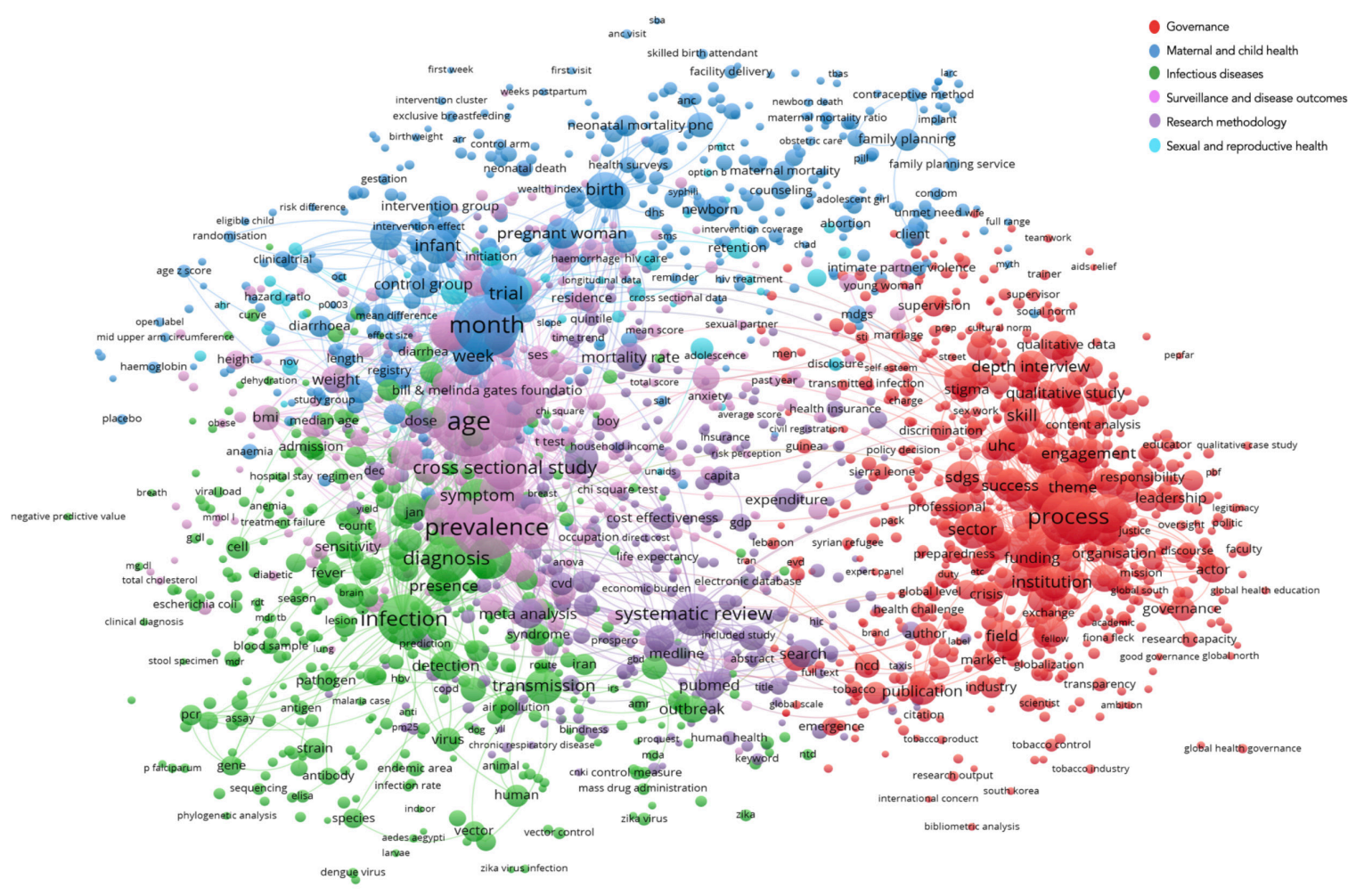

Figure 5 Mapping and clustering of terms in global health journals between 2016 and 2019.

period. The surveillance and disease outcomes cluster moved from focusing on demographic factors to increasingly featuring non-communicable disease outcomes and statistical analyses. This is in line with the global shift to non-communicable diseases as the leading causes of morbidity and mortality. However, non-communicable diseases remain disproportionally under-represented in global health publication given the fact that they are currently, by far, the greatest contributor to the global burden of morbidity and mortality. ${ }^{30}$ Within the governance cluster, publications shifted from a generic focus on policy and context in 2001-2005 to a highlighting research on institutions, UHC and the SDGs in 20152019. This is in line with the adoption of the SDGs in 2015 and the increasing attention to UHC as a goal for all countries to reach. Sexual and reproductive health and research methodology are gaining attention in global health research as major topics. The emergence of the sexual and reproductive health may be due to the increase in funding to the topical area over the best few years. ${ }^{31}$

Importantly, overall, throughout the study period, a biomedical approach was clearly dominant in the type of research published in the journals in our analysis. Other areas of research that affect the health of populations such as economics began to appear in later years. Further, a number of topics that have global implications, such as climate change, antimicrobial resistance, urbanisation, trade and commercial interests, and migration-both voluntary and forced- remain a minority among publications in journals labelled as global health journals.

Finally, our review of global health definitions highlighted a lack of consensus on how to define the field. Global health definitions were not aligned on specific defining characteristics of the field and covered a wide range of topics. Further, the definitions bore little alignment to the topical areas published in global health journals. Generally, definitions emphasised social and economic drivers of health. Few definitions emphasised the geography component of global health and only one definition provided a list of topical areas with a global focus such as climate change. Importantly, none of these definitions explicitly tackled the role existing power dynamics and globalisation have in shaping population health worldwide.

\section{Limitations}

Our analysis has two main limitations. First, the results depend on the global health journals we included in the analysis. These results may differ if we include journals articles published in journals focusing on other social science disciplines such as anthropology and political science. Given the nascency of the field, and how porous its scope, it is likely that publications relevant to global health scholarship are published in journals other than ones that are explicitly about 'global health'. As such, the journals used in our analysis may be considered a repository for a particular type of global health scholarship, 
Table 1 Definitions of the term global health

\begin{tabular}{|c|c|c|}
\hline Reference & Year & Definition \\
\hline Labonte and Spiegel ${ }^{21}$ & 2003 & $\begin{array}{l}\text { The social, environmental and economic contexts in which health, disease and healthcare } \\
\text { interventions are embedded }\end{array}$ \\
\hline Kickbusch $^{20}$ & 2006 & $\begin{array}{l}\text { Health issues that transcend national boundaries and governments and call for actions on } \\
\text { the global forces that determine the health of people }\end{array}$ \\
\hline $\begin{array}{l}\text { Institute of Medicine } \\
\text { (US) Committee on the } \\
\text { US Commitment to } \\
\text { Global }^{22} \text { Health }\end{array}$ & 2009 & $\begin{array}{l}\text { The goal of improving health for all people in all nations by promoting wellness and } \\
\text { eliminating avoidable disease, disability and death. It can be attained by combining } \\
\text { population-based health promotion and disease prevention measures with individual-level } \\
\text { clinical care }\end{array}$ \\
\hline Koplan et al ${ }^{9}$ & 2009 & $\begin{array}{l}\text { An area for study, research and practice that places a priority on improving health and } \\
\text { achieving equity in health for all people worldwide }\end{array}$ \\
\hline Beaglehole and Bonita ${ }^{5}$ & 2010 & Collaborative international research and action for promoting health for all \\
\hline Benatar and Brock ${ }^{23}$ & 2011 & $\begin{array}{l}\text { The science and art of preventing disease, prolonging life and promoting physical and } \\
\text { mental health through organised global efforts for the maintenance of a safe environment, } \\
\text { the control of communicable disease, the education of individuals and whole populations in } \\
\text { principles of personal hygiene and safe living habits, the organisation of healthcare services } \\
\text { for the early diagnosis, prevention and treatment of disease, and attention to the societal, } \\
\text { cultural and economic determinants of health that could ensure a standard of living and } \\
\text { education for all that is adequate for the achievement and maintenance of good health }\end{array}$ \\
\hline Gostin $^{24}$ & 2014 & $\begin{array}{l}\text { A (world) where all people live in conditions that allow them to lead, healthy, productive } \\
\text { lives }\end{array}$ \\
\hline Packard $^{25}$ & 2016 & $\begin{array}{l}\text { Investments in efforts to improve the health of peoples living in resource-poor countries by } \\
\text { governments and organisations in the Global North }\end{array}$ \\
\hline Birn et $a l^{26}$ & 2017 & $\begin{array}{l}\text { Health and disease patterns in terms of the interaction of global, national and local forces, } \\
\text { processes, and conditions in political, economic, social and epidemiological domains }\end{array}$ \\
\hline Claborn $^{19}$ & 2018 & $\begin{array}{l}\text { Health issues that transcend borders, that require a multidisciplinary response and that } \\
\text { probably include a focus on politically and ethically charged global issues such as social } \\
\text { justice, urbanisation, rapid climate change and health inequities }\end{array}$ \\
\hline $\begin{array}{l}\text { Mukherjee and } \\
\text { Farmer }^{27}\end{array}$ & 2018 & The emerging discipline of healthcare delivery in improvised settings \\
\hline King and Koski ${ }^{46}$ & 2019 & Public health somewhere else \\
\hline
\end{tabular}

which is focused on LMICs. However, the goal of this analysis was not to create its own list of global health journals but rather to examine what is currently being published in journals labelled as global health journals. Second, our results provide an overall view of the field rather than a microscopic analysis, which can lead to missing some of the subtle changing in research priorities. We hope that this approach provides a useful first pass at understanding the macroscopic trends in what has been, and is, considered as global health scholarship.

\section{A path forward for global health scholarship}

Our analysis of scholarship in journals labelled as global health journals shows that the field continues to focus largely on topics relevant to LMICs. This can be attributed to either editors' or researchers' preferences or difficulty in publishing scholarship relevant to LMICs in other journals. It can also be due to the preferences of scholars working on topics related to high-income countries to publish in other journals. All of these possibilities indicate that there is an underlying issue in framing what is considered as global health scholarship. This raises the question of whether global health scholarship, despite being regarded as a new discipline, is fundamentally different in nature than its predecessor, international health.

Global health has evolved from international health, at least partially, as an attempt to shed the more colonial roots of international health and focus on health worldwide. ${ }^{26}{ }^{32}$ However, it is not clear that this terminology change has been accompanied by tackling the fundamental intellectual orientation that shapes scholarship and practice. ${ }^{33}$ As such, it can be argued that global health has become a more marketable term than international health rather than a genuine attempt to establish a new field concerned with the health of the global population in mind. ${ }^{34-36}$

Given these realities, we propose that the global health scholarship can potentially take one of two directions. First, global health scholarship can continue to focus on LMICs-related issues but with genuine efforts to address the forces that shaped the scholarship and practice of international health. Such an approach will require deeper interrogation of the power dynamics that underlie the colonial roots of international health. ${ }^{37-43}$ Further, 
the field would need to move beyond the biomedical approach to population health and embrace an approach that acknowledges and addresses the foundational social, economic, political and commercial forces that shape the health of populations in LMICs. This will require centralising disciplines such as anthropology, economics and sociology in global health scholarship.

A second, alternative, approach to the future of global health scholarship would be more transformative and would embrace the global in global health. ${ }^{44}$ This would require, in addition to interrogating global power dynamics, a more intentional approach to both the methods and topics that fall under global health scholarship. Such a shift would require more focus on the issues that affect the global population. One journal that has attempted to so is Globalization and Health. ${ }^{45}$ The journal emphasises that development, economics and trade, governance, foreign policy, and migration and mobility, among others, are important areas of global health research. The world is experiencing global issues such as climate change, rapid urbanisation, rising income inequality, anti-microbial resistance; all of these require a global understanding and action. The global pandemic of COVID-19 is potent reminder of such a need. The field of global health, if suitably reconfigured, can be at the forefront of scholarship and practice that rise to meet these challenges.

\section{CONCLUSION}

There has been tremendous growth in publication in global health journals. The majority of articles published in these journals focus on issues mainly prevalent in lowresource settings. Some topics of great global importance are not currently centre to publications in global health. Definitions of global health, reflecting expert opinion, are largely inconsistent with one another and with the empirical publications in the field. Our results suggest a need to define the parameters of the discipline and investigate the disconnect between what is published in global health versus how the field is defined. Importantly, given its focus on topical areas, the full scope of scholarship that is relevant to global health is most likely not in journals designated for global health. This both suggests the porousness of the global health intellectual agenda and the challenge that the field faces with clearly circumscribing its bounds.

Our analysis reinforces that global health scholarship, as currently construed, is a continuation of its predecessor, international health. Our analysis adds to the emerging critique that holds a mirror to 'what is' in an effort to advance the conversation on 'what should be' global health scholarship and practice. Moving beyond these constraints will require scholars in the field to be self-reflexive about their own thinking and practices, interrogate existing power dynamics, move to consider issues of importance to global population health and adopt a multidisciplinary approach that moves beyond the biomedical method of studying the health of populations.

\section{Twitter Salma M Abdalla @SalmaMHAbdalla}

Contributors SMA and SG-conceived the analysis. SMA-conducted the journal major articles analysis. HS — conducted the search for global health definitions. SMA — drafted the manuscript. All authors—contributed scientifically and revised the manuscript.

Funding The authors have not declared a specific grant for this research from any funding agency in the public, commercial or not-for-profit sectors.

Competing interests None declared.

Patient consent for publication Not required.

Provenance and peer review Not commissioned; externally peer reviewed.

Data availability statement Data are available upon request.

Supplemental material This content has been supplied by the author(s). It has not been vetted by BMJ Publishing Group Limited (BMJ) and may not have been peer-reviewed. Any opinions or recommendations discussed are solely those of the author(s) and are not endorsed by BMJ. BMJ disclaims all liability and responsibility arising from any reliance placed on the content. Where the content includes any translated material, BMJ does not warrant the accuracy and reliability of the translations (including but not limited to local regulations, clinical guidelines, terminology, drug names and drug dosages), and is not responsible for any error and/or omissions arising from translation and adaptation or otherwise.

Open access This is an open access article distributed in accordance with the Creative Commons Attribution Non Commercial (CC BY-NC 4.0) license, which permits others to distribute, remix, adapt, build upon this work non-commercially, and license their derivative works on different terms, provided the original work is properly cited, appropriate credit is given, any changes made indicated, and the use is non-commercial. See: http://creativecommons.org/licenses/by-nc/4.0/.

\section{ORCID iDs}

Salma M Abdalla http://orcid.org/0000-0001-5474-4521

Hiwote Solomon http://orcid.org/0000-0001-9125-5217

\section{REFERENCES}

1 UW News. Universities report doubling of students enrolled in global health programs in last three years. Available: https://www. washington.edu/news/2009/09/14/universities-report-doubling-ofstudents-enrolled-in-global-health-programs-in-last-three-years/

2 Merson $\mathrm{MH}$. University engagement in global health. N Engl J Med Overseas Ed 2014;370:1676-8.

3 Campbell RM, Pleic M, Connolly $H$. The importance of a common global health definition: How Canada's definition influences its strategic direction in global health. J Glob Health 2012;2.

4 Abimbola S. On the meaning of global health and the role of global health journals. Int Health 2018;10:63-5.

5 Beaglehole R, Bonita R. What is global health? Glob Health Action 2010;3:5142.

6 Mason PH, Kerridge I, Lipworth W. The global in global health is not a given. vol. 96, American Journal of tropical medicine and hygiene. American Society of Tropical Medicine and Hygiene 2017:767-9.

7 Sheikh K, Schneider H, Agyepong IA, et al. Boundary-spanning: reflections on the practices and principles of global health. BMJ Glob Health 2016;1:e000058.

8 Taylor S. 'Global health': meaning what? BMJ Glob Health 2018;3:e000843.

9 Koplan JP, Bond TC, Merson MH, et al. Towards a common definition of global health. Lancet 2009;373:1993-5.

10 Evans JA, Foster JG. Metaknowledge. Science 2011;331:721-5.

11 Griffiths TL, Steyvers M. Finding scientific topics. Proc Natl Acad Sci U S A 2004;101 Suppl 1:5228-35.

12 Trinquart L, Galea S. Mapping epidemiology's past to inform its future: metaknowledge analysis of epidemiologic topics in leading journals, 1974-2013. Am J Epidemiol 2015;182:93-104.

13 Bhaumik S, Jagnoor J. Diversity in the editorial boards of global health journals. BMJ Glob Health 2019;4:e001909.

14 Nafade V, Sen P, Pai M. Global health journals need to address equity, diversity and inclusion. BMJ Glob Health 2019;4:e002018.

15 Waltman L, van Eck NJ, Noyons ECM. A unified approach to mapping and clustering of bibliometric networks. J Informetr 2010;4:629-35 
16 Van Eck NJ, Waltman L. VOS: A new method for visualizing similarities between objects. In: Studies in classification, data analysis, and knowledge organization, 2007: 299-306.

17 CERN. R: the R project for statistical computing. Available: https:// www.r-project.org/

18 VOSviewer. Visualizing scientific landscapes. Available: https://www. vosviewer.com/

19 Claborn D M. Introductory chapter: what is global health? in: current issues in global health. IntechOpen 2018.

20 Kickbusch I. The need for a European strategy on global health. Scand J Public Health 2006;34:561-5.

21 Labonte R, Spiegel J. Setting global health research priorities. BMJ 2003;326:722-3.

22 Institute of Medicine (US) Committee on the US Commitment to Global Health. The U.S. commitment to global health: recommendations for the public and private sectors. The U.S. commitment to global health: recommendations for the public and private sectors National Academies Press; 2009: 1-276.

23 Benatar S, Brock G. Global health and global health ethics, 2011: 1-342

24 Gostin LO. Global health law. Harvard University Press, 2014. https://www.hup.harvard.edu/catalog.php?isbn=9780674728844

25 Packard RM. A history of global health : interventions into the lives of other peoples. Baltimore: Johns Hopkins University Press, 2016: 414

26 Birn A-E, Pillay Y, Holtz TH. Textbook of global health. Oxford University Press, 2017. http://www.oxfordscholarship.com/view/10. 1093/acprof:oso/9780199392285.001.0001/acprof-9780199392285

27 Mukherjee JS, Farmer P. An introduction to global health delivery. Oxford University Press, 2017. https://global.oup.com/academic/ product/an-introduction-to-global-health-delivery-9780190662455? $\mathrm{cC}=$ us\&lang $=\mathrm{en} \&$

28 United Nations. United nations millennium development goals, 2020 Available: https://www un org/millenniumgoals/

29 Dieleman JL, Schneider MT, Haakenstad A, et al. Development assistance for health: past trends, associations, and the future of international financial flows for health. Lancet 2016;387:2536-44

30 JamesSL, AbateD, AbateKH, et al. Global, regional, and national incidence, prevalence, and years lived with disability for 354 diseases and injuries for 195 countries and territories, 1990-2017: a systematic analysis for the global burden of disease study 2017. Lancet 2018;392:1789-858.
31 Schäferhoff M, Van Hoog S, Martinez S, et al. Funding for sexual and reproductive health and rights in low-and middle-income countries: threats outlook and opportunities OPEN CONSULTANTS STUDY COMMISSIONED BY: The Partnership for Maternal, Newborn \& Child Health.

32 Brown TM, Cueto M, Fee E. The World Health Organization and the transition from "international" to "global" public health. Am J Public Health 2006;96:62-72.

33 Bozorgmehr K. Rethinking the 'global' in global health: a dialectic approach. Global Health 2010;6:19.

34 Eichbaum QG, Adams LV, Evert J, et al. Decolonizing global health education: rethinking institutional partnerships and approaches. Acad Med 2020. doi:10.1097/ACM.0000000000003473. [Epub ahead of print: 28 Apr 2020]

35 Shiffman J. Knowledge, moral claims and the exercise of power in global health. Int J Health Policy Manag 2014;3:297-9.

36 Sridhar D. Who sets the global health research agenda? the challenge of multi-bi financing. PLoS Med 2012;9:e1001312.

37 Sriram V, Topp SM, Schaaf M, et al. 10 best resources on power in health policy and systems in low- and middle-income countries. Health Policy Plan 2018;33:611-21.

38 Gill S, Benatar S. Global health governance and global power. Int $J$ Health Serv 2016;46:346-65.

39 Gore R, Parker R. Analysing power and politics in health policies and systems. Glob Public Health 2019;14:481-8.

40 Shiffman J. Global health as a field of power relations: a response to recent commentaries. Int J Health Policy Manag 2015;4:497-9.

41 Moon S. Power in global governance: an expanded typology from global health. Global Health 2019;15:74.

42 Benatar S. Politics, power, poverty and global health: systems and frames. Int J Health Policy Manag 2016;5:599-604.

43 Marten R. Global health warning: definitions wield power comment on "navigating between stealth advocacy and unconscious dogmatism: the challenge of researching the norms, politics and power of global health". Int J Health Policy Manag 2016;5:207-9.

44 Byass P. Is global health really global? Glob Health Action 2013;6:20671.

45 Labonté R. Reprising the globalization dimensions of international health. Global Health 2018;14.

46 King NB, Koski A. Defining global health as public health somewhere else. BMJ Glob Health 2020;5:e002172. 